\title{
Article \\ The Role of Natural Factors on Major Climate Variability in Northern Winter
}

\author{
Indrani Roy \\ College of Engineering, Mathematics and Physical Sciences, University of Exeter, Laver Building, \\ Streatham Campus, North Park Road, Exeter EX4 4QE, UK; I.Roy@exeter.ac.uk; Tel: +44-(0)1392-723-628; \\ Fax: +44-(0)1392-217-965
}

\begin{abstract}
This work studies the role of natural factors mainly solar eleven-year cycle variability, and volcanic eruptions on two major modes of climate variability the North Atlantic Oscillation (NAO) and El Niño Southern Oscillation (ENSO) for around last 150 years period. The NAO is the primary factor to regulate Central England Temperature (CET) during winter throughout the period, though NAO is impacted differently by other factors in different time periods. Solar variability has a positive influence on NAO during 1978-1997, which is opposite before that period. Solar NAO lag relationship is also sensitive to the chosen times of reference. Such analyses raise a question about previously proposed mechanism and relationship related to the sun and NAO. The ENSO is seen to be influenced strongly by solar variability and volcanic eruptions in certain periods. This study observes a strong negative association between solar variability and ENSO before the 1950s, which is even opposite during the second half of 20th century. The period 1978-1997, when two strong eruptions coincided with active years of strong solar cycles, the ENSO, and volcanic eruptions suggested the stronger association. Here we show that the mean atmospheric state is necessary for understanding the connection between solar variability, the NAO and ENSO and associated mechanism.
\end{abstract}

Keywords: solar variability; NAO; ENSO; volcanic eruptions; multiple regression

\section{Introduction}

The Sun provides the fundamental source of energy for the climate system, but the level of scientific understanding relating to its influences on a climate of the earth is still low. Though regarding terms of energy output, there is only a $0.1 \%$ change from maximum to minimum years of the 11-year cycle [Lean and Rind, 2001], too negligible to influence climate but studies identified the significant regional impact that is felt seasonally and also depend on overall period chosen. Earlier reports of Intergovernmental Panel on Climate Change (IPCC) have included assessment of the solar influence with the overall conclusion that the Sun may have played a role in influencing the climate but that the "level of scientific understanding" was poor. In understanding climate variability and in interpreting signals of climate change it is important to ascertain the role of natural factors so that any human influence may be more accurately identified.

Nowadays, there is universal agreement that the direct impact of the changes in the UV part of the spectrum ( 6 to $8 \%$ between solar maxima and minima) leads to more ozone and warming in the upper stratosphere in solar maxima (discussed in details by Gray et al. (2010)). Ozone variation in the stratosphere during the 11-year solar cycle can impact lower stratosphere and subsequently, troposphere has been shown by Haigh [1996] and Haigh et al. [2005] using a simplified general circulation model (GCM). The variation of ozone, through absorption of solar UV spectrum around upper stratosphere, is one responsible factor for controlling temperature gradient between summer hemispheres to that from winter hemisphere. Subsequently, through the well-known thermal wind balance relationship, the solar cycle can regulate the strength of polar vortex, suggesting a stronger stratospheric polar jet in active solar years and vice versa. Baldwin and Dunkerton [2001] showed perturbation in the polar vortex can affect the polar troposphere during the same season. Kodera and Kuroda [2002] proposed a mechanism, whereby active solar years have the potential to influence the 
polar vortex and subsequently down to the lower tropical stratosphere, which also involve upward propagating planetary waves. All these mechanisms, by which, solar variability that affects the stratosphere are transported downwards and subsequently influences tropospheric climate is well accepted and known as solar 'Top-Down' mechanism.

Ineson et al. [2011] analysed the regional impact of the solar 11-year cycle on North Atlantic Oscillation (NAO) during northern winter by using UK Met Office Unified Model and found an in-phase relationship between the sun and NAO. They imposed a vast change in solar UV irradiance to produce their observed response. It is interesting to analyse the robustness of such proposed association between the sun and NAO, and the current study explores that area. In improving knowledge about climate variability, it is important to ascertain the actual role of natural factors. Moreover, such understanding will also help improving future prediction skill.

Apart from variations in the sun, another major natural variability is volcanic eruptions and discussed in details by Robock [2003]. Major eruptions can eject short-lived ash and gases (sulphur dioxide etc.) high into the atmosphere. Sulphur dioxide then converts to sulphate aerosols and stay in the air for more years and block incoming solar radiation. Thus, the radiative effect of volcanic eruptions is global cooling irrespective of the period considered, but its actual effect around continents of the Northern Hemisphere (NH) suggests winter warming [Robock and Mao, 1992] and needs attention. Using reanalysis data of the 20th Century version 2 (20CRv2), [Compo et al., 2011], a significant surface warming over northern Europe and Asia was detected by Driscoll et al. [2012]. They showed that the surface temperature in the Arctic region appeared anomalously warm during post-volcanic winter season. Results from Coupled Model Intercomparison Project 5 (CMIP5) simulations [Driscoll et al. 2012], concluded that the models fail to capture the $\mathrm{NH}$ dynamical response following eruptions and raises issues about the inability of current climate models to simulate the effect of a dominant mode of variability namely NAO to external forcing. More study is required to explore the connection between volcano and NAO.

The El Niño Southern Oscillation (ENSO) is another major climate variability which is originated via atmosphere and ocean coupling. Through different teleconnections, it affects almost all parts of the globe. There is enough evidence that suggests that the low-frequency variability of ENSO is primarily modulated by decadal variability in the North Pacific [Latif et al. 1997; Gu and Philander 1997]. The decadal mode of ENSO might be related to solar 11-year cycle. Applying Empirical Orthogonal Function (EOF) technique on SST, White et al. [1997, in their Fig 6, Top] using data from the latter period of the 20th century showed that tropical Pacific SSTs resemble positive phase of the ENSO. It is also in phase with the 11-year solar cycle. Whereas using the Method of Solar Maximum Compositing van Loon et al. [2007], and Meehl et al. [2008] detected an enormous negative signature in tropical Pacific SST for 150 years period, matching that of the negative phase of ENSO. Using the same dataset, over a similar time Roy and Haigh [2010] could not detect negative solar signal around tropical Pacific using Regression Technique. Haam and Tung [2012], Roy and Haigh [2010, 2012], Roy [2010, 2013] addressed those contradictory findings in details and reconciled some of the contradictions and discussed few mechanisms. Discussions still suggest that the solar-ENSO behaviour is a major area of dispute in climate science. More critical analyses and thorough investigations are highly required to understand the exact nature of the ENSO sun connections and its implication to global scale climate responses.

Yeo and Kim [2014, Fig 1], using the method of CycloStationary Empirical Orthogonal Function (CSEOF) analysis, detected three independent primary global modes of SST variability in the tropical Pacific. The first mode exhibited a clear trend and represented global SST warming with an 'El Niñolike' SST pattern. The second mode suggested a close connection between tropics and north Pacific and acts on inter-annual and decadal time scales. The ocean-atmosphere coupled system drove the third mode and showed a seesaw pattern between El Niño and La Niña within a two-year period. Latif et al. [1997] using the technique of principal oscillation pattern (POP) analysis also identified these three modes of tropical Pacific SST variability. 
The connection between ENSO and volcano is another interesting area that needs attention. Regardless of solar forcing, Emily-Geay et al. [2008] showed, explosive volcanos, with a radiative forcing greater than 3.3 to $4 \mathrm{Wm}-2$, noticeably influence the modelled ENSO. Those are roughly the magnitude of the Krakatau and Pinatubo eruptions. Such eruptions can even significantly raise the likelihood of an El Niño event above the model's internal variability level. The response of ENSO from explosive volcanism was studied by Adams et al. [2003] by using two different paleoclimate reconstructions of El Niño activity and two independent, proxy-based chronologies from AD 1649. They found a significant, multi-year, El Niño-like response over the past several centuries and showed nearly twice the probability of an El Niño occurrence in the winter following a volcanic eruption. A modelling study [Iles et al., 2013] suggested, in boreal winter, the magnitude of global hydrological responses under volcanism is significantly underestimated. The difference arises from the wet tropical regions, which shows improvements when the ENSO is removed. All these indicate studies relating to the effect of explosive volcanism on ENSO needs further exploration.

This paper addresses some of these issues to improve understanding of the role of natural factors, by using observational data. It also discusses some of the existing mechanisms in support. Such knowledge about natural variability has implications for improving future prediction skills. Modelling studies are still unable to address certain crucial parts, as the mechanism related to natural forcing lacks in understanding. This paper addresses such issues so that models can also incorporate such findings and improve performance.

The structure of the study is as follows. Section 2 discusses Methodology and Data. Results are detailed in section 3 and have four sub-sections. The first sub-section (3.1) covers analyses using time series of various factors. The first part discusses the general behaviour of different indices and their combined effect while second part details results of regression using various indices. Section 3.2 analyses data to identify the spatial signature and section 3.3 addresses on a potential mechanism. Few questions on Sun NAO lag relationship is raised in section 3.4, and the results are summarised in section 4 .

\section{Methodology and Data.}

The method we used here is the method of Multiple Linear Regression (MLR) analysis with AR(1) noise model. Here noise coefficients are calculated simultaneously with the components of variability such as the residual matches with an order one red noise model. Following this methodology, it is possible to minimise noise being interpreted as a signal. The code is developed by Prof. Myles Allen, University of Oxford (personal communication).

Multiple linear regression may be represented as:

$$
\mathbf{y}=\beta \mathbf{X}+\mathbf{u}
$$

Here ' $y$ ' is a vector of rank $n$ containing the time series of the data. ' $X$ ' is a matrix of order $n x m$, comprising time series of $m$ indices, which are thought to influence the data. ' $\beta$ ' is a vector of rank $m$ that contains amplitudes of the indices, that we intend to estimate. ' $u$ ' is the noise term which is unobserved and may arise due to various sources (e g., internal noise, all sources of observational error, un-modelled variability, etc.). We estimate amplitudes of variability due to different climate factors using autoregressive noise model order one (AR(1)). Using a noise model of higher order does not make much difference to the results. Finally, using the Student's t-test the level of confidence in the value of $\beta$ derived for each index is estimated.

Here is a little elaboration of the methodology. First, the autocorrelation and variance of the noise are estimated from the residual $(y-b X$, where ' $b$ ' is an estimate of ' $\beta$ '). Then a red noise function assumed to be of order one is fitted to the residual. Afterwards, the values of ' $b$ ' and noise parameters 
are iterated until the noise model fits within a pre-specified threshold. It also produces, using Student's t-test, measures of the confidence intervals of the resultant ' $b$ ' values taking account of any covariance between the indices.

The method is also used in various studies those include Roy and Haigh (2011), Roy and Collins (2014) and Roy (2010, 2013), Gray et al. (2010) and Gray et al. (2013), etc.. In the MLR technique there could be issues for not using purely orthogonal set of independent variables. The results might also have an aliasing problem. Those issues were discussed in Roy (2013). Almost every cases the signals were shown to be robust and does not change if we exclude a parameter from the regression. Variables and climate indices used in this analysis are Sea Level Pressure (SLP), monthly Sun Spot Number (SSN), Niño3.4, Stratospheric Aerosol Optical Depth (AOD), (indicative of volcanic eruptions), longer term trends, Central England Temperature (CET) and North Atlantic Oscillation (NAO). For SLP, the in-filled HadSLP2 dataset from Allan et al. [2006], that covers the whole globe and available as monthly means from 1850 to 2004 are used. It can also be found from http://www.metoffice.gov.uk/hadobs/hadslp2. Unlike HadSLP1, error estimates are mentioned for HadSLP2, to have ideas about the regions of little confidence. Measurement and sampling errors are large in the high southern latitude due to the lesser number of observations, though it is small in other areas. The estimates lie between the observational error estimates of Kent et al. (1997) of $2.3 \pm 0.2$ $\mathrm{hPa}$ and those of Ingleby (2001) of $1 \mathrm{hPa}$ over most of the ocean basins. Monthly Sun Spot Number (SSN) is used to represent solar cyclic variability and collected from ftp://ftp.ngdc.noaa.gov/STP/ SOLAR_DATA/SUNSPOT_NUMBERS/INTERNATIONAL/ monthly/MONTHLY.PLT. The main advantage of using SSN as a solar index is that it is free from the influence of trends and only captures the cyclic variability of the Sun. Hence, SSN is the most commonly used solar index for analysing long-term climate data. The eleven-year cyclic nature of SSN can also be used as a practical and useful feature for prediction purpose. For ENSO, Niño 3.4 index, obtained from Kaplan et al. [1997] is used which is available since 1856 and can also be found at http://climexp.knmi.nl. In the regression AOD has been employed to represent volcanic eruptions and collected from Sato et al. [1993], which is available up to 1999 and can also be found at https://data.giss.nasa.gov/modelforce/strataer/tau_line.txt.. It has been extended to 2005 with near zero value. Longer term trend is a rising linear line that represents increasing anthropogenic influence of the 20th century. In this analysis, NAO index from Climate Research Unit (CRU), University of East Anglia is used which is available since 1823. It is developed by Jones et al., (1997) that considered instrumental pressure observations from Gibraltar and south-west Iceland. It is also available from http://www.cru.uea.ac.uk/ timo/projpages/nao_update.htm.

Central England Temperature (CET) data is available from 1659, and this is the longest record of station data and described in various publications [Manley et al. (1974), Parker et al. (1992), Parker and Horton (2005)] and also available from http://www.metoffice.gov.uk /hadobs/hadcet/data/download.html.

\section{Results:}

\subsection{Analyses using time series of various factors:}

\subsubsection{General behaviour of different indices and their combined effect:}

The Fig. 1 is time series plot of different parameters. Fig. 1(i) shows global surface air temperature anomalies w.r.t. 1951-1980 base period (after Hansen et al., 2010, also available on the web, http://data.giss.nasa.gov/gistemp/2011/, Fig.2). Annual value is shown by black and 5-year running means by red. Fig. 1(ii) shows time series of various independent factors those are likely to influence surface temperature. First plot (Fig. 1(ii)) on top (a) is the linear trend that represents longer term climate change and mainly arises due to anthropogenic influence. The second plot from top (b) is due to AOD, and the third (c) and fourth (d) are due to solar eleven-year cycle variability (here SSN) and Niño3.4 index (representing ENSO) respectively. 


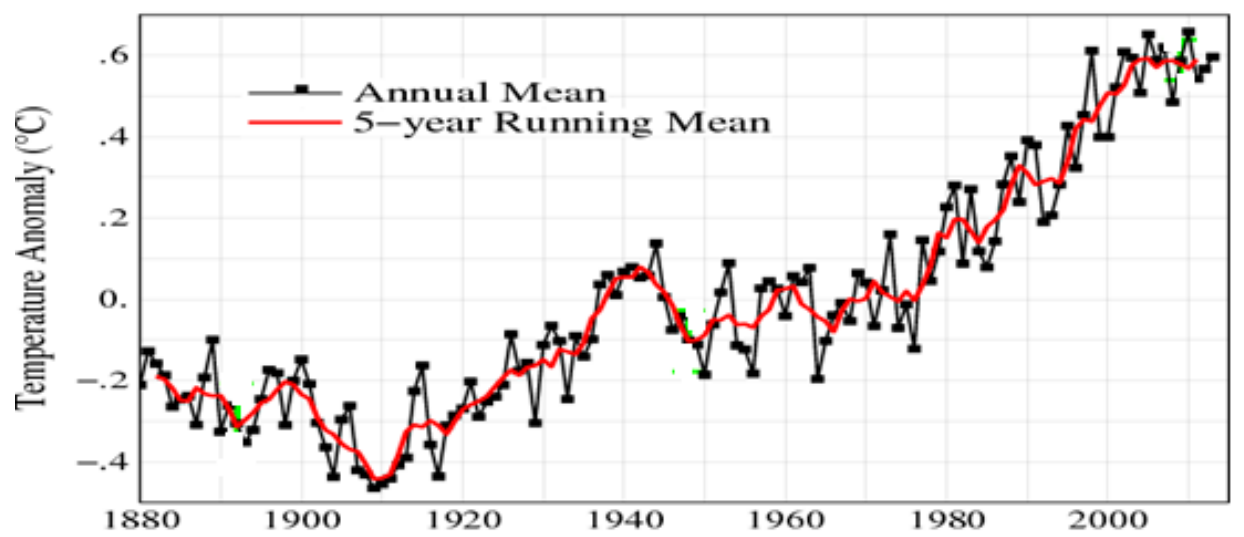

(i)
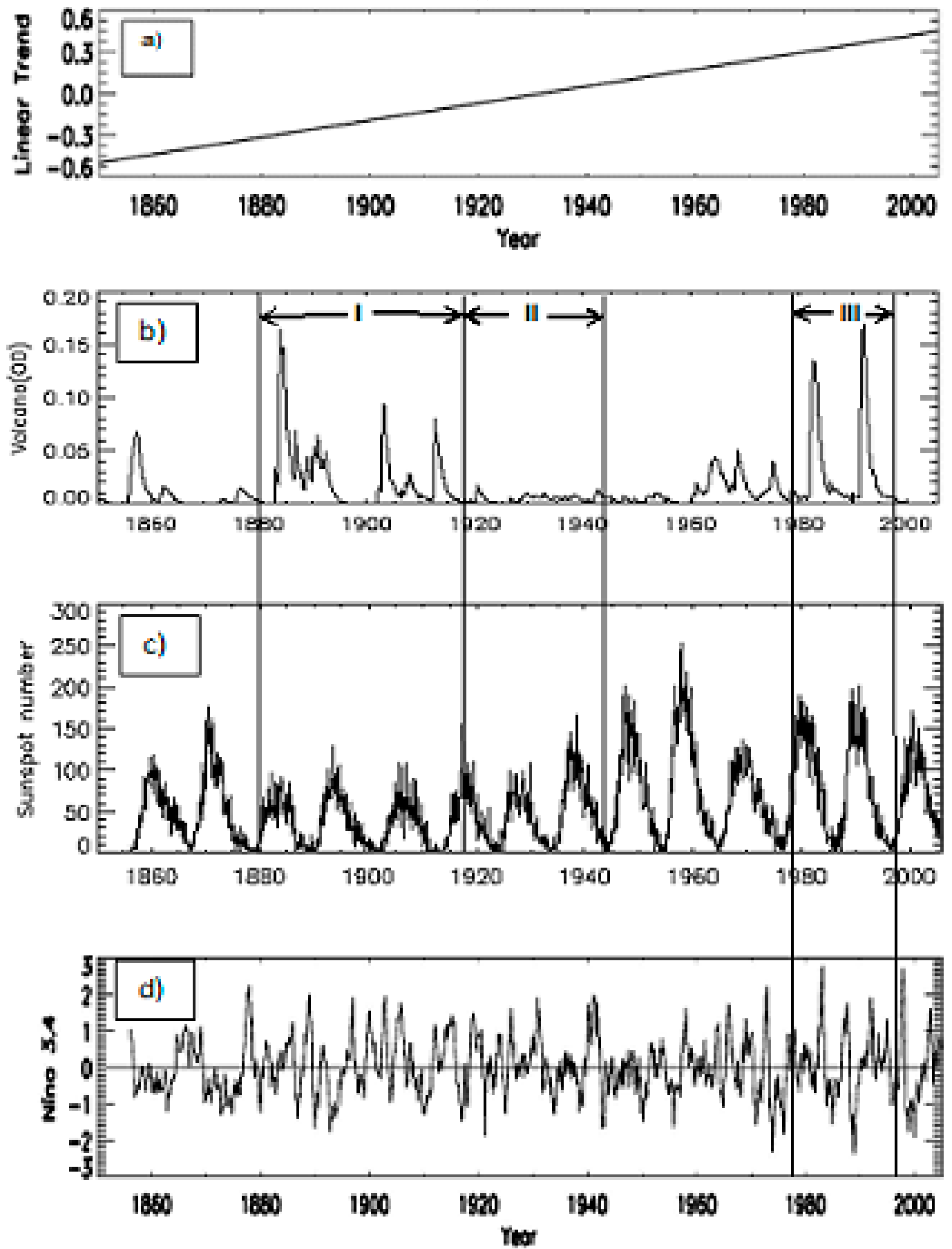

(ii) 
Fig. 1: Time series of various independent parameters (Fig. 1(ii)), that affect global surface air temperature (Fig. 1(i)). Fig. 1(i). Global surface air temperature anomalies relative to 1951-1980 base period (after, Hansen et al., 2010). Fig. 1(ii): Time series of a) normalised linear trend (top), b) Stratospheric Aerosol Optical Depth (AOD) (2nd row), c) Sunspot number (SSN) (3rd row) and d) ENSO, represented by Niño3.4 Index $\left({ }^{\circ} \mathrm{C}\right)$ (bottom). Three periods (I, II and III) are marked based on various combinations of the strength of volcanic activity and solar irradiance for I) cooling of surface temperature; II) rise in surface temperature and III) abrupt rise in surface temperature.

Due to a large specific heat of ocean, it can retain heat for longer time scale and thus longer term variation of solar output is captured and detected mainly in the oceans. The Atlantic Multi-decadal Oscillation (AMO) and Pacific Decadal Oscillation (PDO) are two primary modes of variability in the Northern Hemisphere (NH) with longer time scales which are generated due to atmosphere and ocean coupling and substantially regulate global temperature. In the current study, the primary interest is on the role of climate variability on time scales of decades and less and thus, PDO and AMO, which have a longer-term variability of 20-30 years are not included. Moreover, those are not considered as an independent variable; rather they are the regional manifestation of longer-term SST variability.

Here is a brief discussion about global surface temperature variation as it corresponds to Fig.1(i). In that plot, there is an apparent rise in temperature noticed during 1917 to 1944. There is a cooling trend before that period. The sharp increase is again seen since 1978 that continued up to 1997. Three phases (I, II and III) are marked in Fig 1(ii) based on various combinations of the strength of volcanic activity and solar irradiance, which also follows the variation of surface temperature (Fig. 1(i)). Period (I) suggests cooling of surface temperature, period (II) indicates a rise in surface temperature; whereas, period (III) shows an abrupt increase in surface temperature.

The sun and volcano:

During the latter half of 20th century, the period dominated by the sudden rise in surface temperature, the solar cycles are also seen to be stronger as noticed in Fig. 1(ii). In addition, three major volcanos erupted during 1963, 1982 and 1991 and last two even coincided with the near peak of active solar cycles. Though the solar peaks and volcanic eruptions occurring simultaneously are a pure coincidence, if it happens, it changes the mean state of stratosphere and troposphere.

Volcanic aerosols also have the potential to change stratospheric chemistry with most necessary chemical changes in the stratosphere related to ozone [Robock, 2003]. After the 1991 Pinatubo eruption, ozone column reduction of about $5 \%$ was observed in between mid-latitudes of both the $\mathrm{NH}$ and Southern Hemisphere (SH). Considering ozone depletion in the aerosol cloud, it was much larger (20\%). Thus, if intense volcanic eruptions and atmospheric dynamics come together with the right timing, they could reinforce one another with different drastic results. It is interesting to analyse the role of last two eruptions, considering the phase of solar cycles. It has the potential for different dynamical effects including altering the strength and nature of solar so-called 'Top-Down' mechanism. Moreover, ocean-atmosphere coupling system is also disturbed. Thus, both the direct (radiative) and indirect (dynamical) effects of the intense eruptions need to be taken into account actually to judge its contribution in surface climate.

Here is a brief discussion of various combinations of the volcano and solar phases. The late 1800s to the early 1900s was a very active period of volcanic eruptions. Together with a quiet sun that period (marked by 'I', Fig. 1(ii)) was very cold as seen in Fig. 1(i). While the period during 1917 to 1944 was a period of very little volcanic activity that coincided with an increase in solar irradiance (Fig 1, marked by II). This period experienced a warming of global temperatures (Fig.1(ii)). However, the primary focus here is during the time with a steep rise in temperature at last two decades of the 20th century (Fig 1(i)) and the role of natural variability. There was an abrupt increase in surface temperature during 1978-1997 [IPCC, 2013] when two very active volcanos erupted during near peak of active solar cycles (Fig. 1(ii), period III). 
Now, not only the strength of eruption and the power of solar cycle necessary but also their combined behaviour that includes the timing of eruption relating to the phase of solar cycle are important in controlling the climate of the earth. Thus, it is interesting to investigate the role played by major variability individually and in combination, considering the dynamical and radiative influences with attention.

The role of ENSO:

The bottom plot of Fig.1(ii) is for ENSO, which shows the inter-annual variability of 2-7 years. It was usually of 2-3 years cycle during the earlier period and even 5-7 years cycle during the latter period of 20th century. In that figure, the period 1978-1997 is marked (Fig. 1(ii), period III) when ENSO was different from other periods as discussed by various studies. Here discussion relating to ENSO is only based on period III, as earlier period shows usual ENSO behaviour.

Using five months running mean of Niño3.4 SST index, to represent ENSO, Trenberth and Hoar [1997, Fig 1] clearly identified highest ENSO signal during 1982 and that with the longest duration during 1992. They mentioned that from March 1991 to March 1995, the average ENSO did not change sign suggesting those peaks were clearly linked. The warming of the tropical Pacific from 1990 to mid-1995 was unprecedented in the observational record for more than a century [Trenberth and Hore, 1996]. Wang and Fiedler [2006] discussed that there was a failure to recognise the 1982-1983 El Niño (the strongest one over a hundred year period) until it was well developed. They also discussed the unusual nature of warm events of ENSO during 1990-1995 in the context of an observed trend for fewer La Niña and more El Niño events after the late 1970s. The mean SO index for the post-1976 period is statistically different $(<0.05 \%)$ from the overall mean and also the period 1990-mid-1995 [Trenberth, 1997].

Interestingly, the SST trend along the equator in the final 50 years of the 20th century shows an El Niño-like pattern which is robust for all observations using different datasets. However, there are controversies for the trend pattern of the historical SST observations, as it differs substantially among datasets and time periods [Liu et al., 2005]. Though the decadal variation of the tropical climate has a considerable contribution to the ENSO variability [Fedorov and Philander, 2000], the amplitude of the ENSO variability still suggested a robust, rising trend during that period, even removing that contribution [Zhang, et al. 2008].

Qiong, et al. 2008 showed the standard deviation of Niño-3 SST increases to around $0.9^{\circ} \mathrm{C}-1.0^{\circ} \mathrm{C}$ during the last two decades of 20th century and showed a nearly $50 \%-60 \%$ rise in the ENSO variability (significant at the $95 \%$ confidence level). Fig 1(ii) (bottom panel, Period III) agrees with such observations and suggests that the number of El Niño outnumbers to that of La Niña during 1978-1997 with a significant rise of its variability and duration. Such observation explains why SST trend along the equator in the final 50 years of the $20^{\text {th }}$ century shows a robust El Niño-like pattern for all observations using different datasets as observed by Liu et al., 2005.

There is a good correspondence between the ENSO and temperature of troposphere [Sobel et al., 2002], with warm periods coincide with El Niño's whereas, the cold with La Niña's. At the warm phase of ENSO, the troposphere is capable of carrying more water vapour. In a clear sky, water vapour is the most important greenhouse gas that constitutes $60 \%$ of total radiative forcing [Kiehl and Trenberth, 1997]. Ranked by their direct contribution, the largest greenhouse gas compounds are water vapour, and clouds (36-72\%) which have far higher contribution than that of $\mathrm{CO} 2(9-26 \%)$. It indicates the role of water vapour and cloud, associated with the ENSO needs attention.

Considering water vapour as the most important greenhouse gas and noting the fact of fewer La Niña and more El Niño events after the late 1970s (also seen in Fig.1(ii), bottom panel, period III), the rise in global temperature during that time, the different behaviour of El Niño that includes increase in amplitude and time period could be one interesting area which needs to be revisited. More research is required in that direction to advance future prediction skill. The focus here is mainly on natural forcing, and it can also be noted that radiative cooling due to volcanic eruptions may override El Niño warming. 
The overall analyses presented are indicative of studying the importance of combined behaviour of ENSO, volcanic eruptions, and solar variability. In addition to their individual influences, such combination is necessary to understand the overall climate impact regionally as well as globally, and it has implication on future prediction.

\subsubsection{Results of regression using various indices:}

This section presents discussion based on MLR technique. MLR technique is applied to three different parameters CET, NAO and ENSO in three subsequent columns (I, II and III) and presented in Table 1. The first column (I) shows the value of regression coefficients using CET as the dependent parameter, with the independent factors as the NAO, SSN, AOD, ENSO, and trend. The second column (II) is the result due to SSN, AOD, ENSO and trend as independent parameters with NAO being the dependent factor. Whereas, the third column (III) calculates regression coefficients for ENSO as the dependent variable with SSN, AOD, and trend as independent factors.

Table 1. Regression Coefficients for various indices during DJF in different time periods. Values significant at $90 \%, 95 \%$ and $99 \%$ level derived using a Student t-test are shown by *,** and *** respectively.

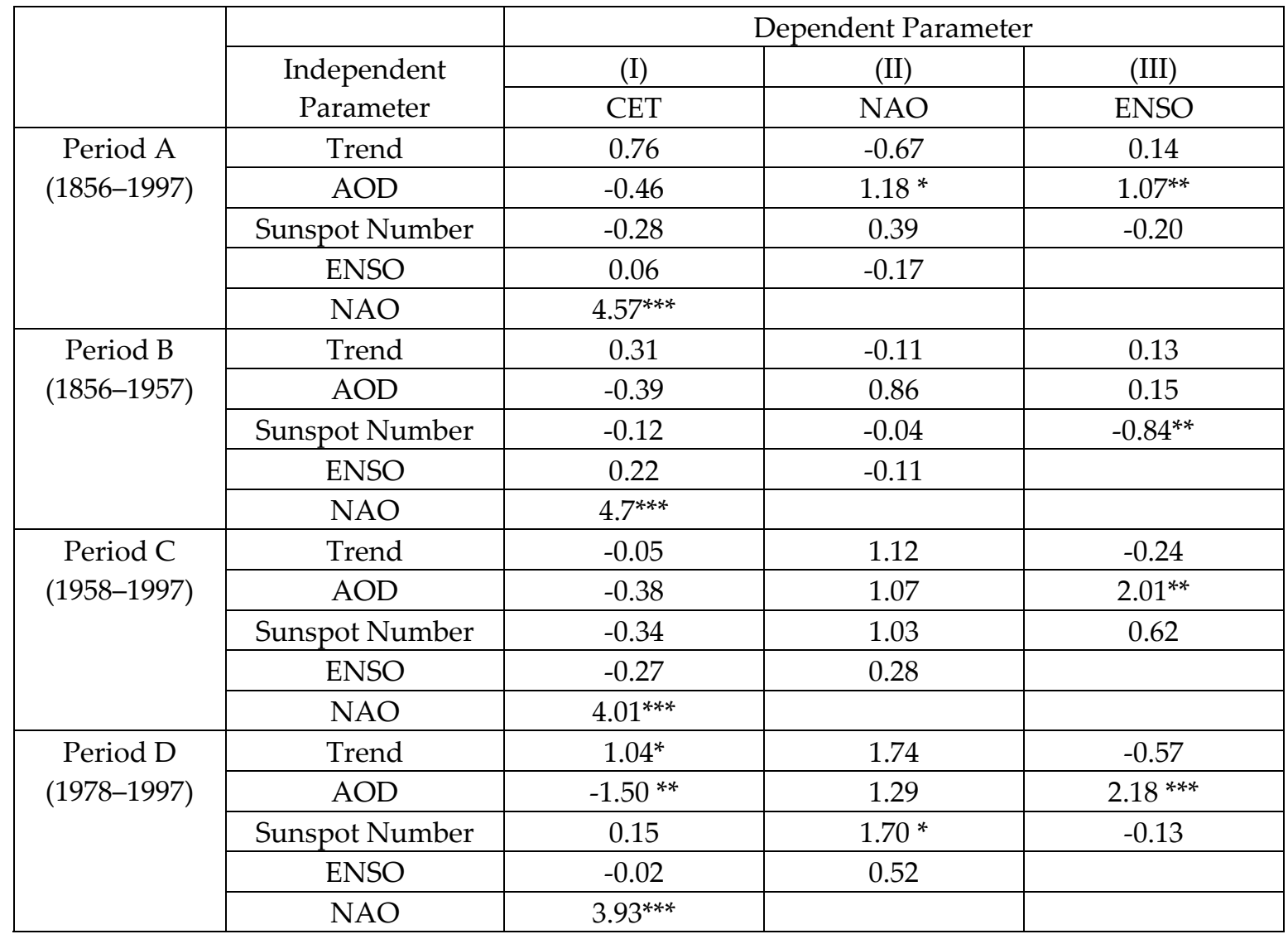

The period from the 1950s to 1997 was identified by several authors [e.g. Vecchi and Soden, 2007] as the period of a weakening of both the Walker and Hadley circulations; more in the Walker than the Hadley circulation. Relating to the strength of Hadley circulations, Nguyen et al. (2013) however discussed that it varied in various reanalyses datasets.

On the other hand, over the same time, the shallow ocean Meridional Overturning Circulation in the Tropical Pacific was also weakened [Zhang and McPhaden, 2006], suggesting that both the atmosphere and the ocean system was in an anomalous state. Hence, that period is separated to that from the earlier period to find the influence of different factors.

Various studies indicated the year 1976/77 as climatic 'regime shift' [Miller et al. 1994, Meehl and Teng, 2014] because many physical conditions in the atmosphere and ocean including surface 
temperature changed abruptly during that period. Substantial evidence also supports the idea that physical conditions changed around atmosphere [Minobe 2000; Bond et al. 2003] and ocean [McPhaden and Zhang, 2004; Vecchi and Soden, 2007] during 1998. Moreover, last two very active volcanos erupted during that intervening period (1978-1997) coinciding the active phase of strong solar cycles. Hence, those two decades are also separated.

In Table 1, period 'A' is for the entire period of consideration up to 1997 which is (1856-1997); whereas, period ' $\mathrm{B}$ ' only considers the time before 1957; period ' $C$ ' is after 1958, while period ' $\mathrm{D}$ ' focuses the time 1978-1997. We also repeated the analysis of period ' $\mathrm{D}$ ' up to 2004 that covers 26 years period, but the main findings did not change. It is because there could be issues related to lesser data points. But the similar period was also analysed by MLR technique in numerous highly cited studies as shown by Gray et al. (2010). The results of significance in different degrees $(90 \%, 95 \%$, and $99 \%)$ are marked by various symbols $\left({ }^{*},{ }^{* *}\right.$ and ${ }^{* * *}$ respectively). However, the primary results are based only on the significant level of $95 \%$ and $99 \%$.

\section{Influence on CET (column I):}

In column I of Table 1, it is clearly seen that the NAO explains most of the variance for CET and the result is $99 \%$ significant in all the periods (A-D). Interestingly, during period D, volcano suggests cooling (95\% significant) in central England, while linear trend indicates warming (90\% significant). Irrespective of time periods considered, NAO plays a dominant role in regulating the temperature of England. Though the influence of NAO on CET is robust, NAO is seen to be influenced by other independent factors differently during different periods considered.

\section{Influence on NAO (column II):}

Identifying the importance of NAO in controlling the temperature of Europe, Central England being one of the representative regions, it is now interesting to determine how NAO can be influenced by other factors and shown in column II. Studies suggested that there are preferences of positive phases of NAO in climate change scenarios [Visbeck, 2001]. It is consistent with the observation for trend during period $\mathrm{C}$ and $\mathrm{D}$, though only significant at $80 \%$ level. Volcano though shows positive connection with NAO throughout the period (A-D), only significant at $90 \%$ level for period A. It is likely that the number of total occurrence of volcanos in period A might have a role. The regression coefficient in period D (+1.29) is seen to be higher than that in period A $(+1.18)$, but because of lesser data points, it fails to indicate the significant result. Such positive connection between volcano and NAO is also noted by Gray et al [2013, Fig. 3] using MLR technique for over a 150 years of observational data.

Now the focus is on solar NAO behaviour. It is seen that over the recent period (post-1957), the relationship between SSN and NAO has strengthened. From column II, Table 1, it is seen that the NAO is influenced positively by SSN during period D (level of significance $90 \%$ ) and C (only $80 \%$, hence not marked) and the nature of this signature is consistent with the recent study by Ineson et al. [2011]. Considering the period of latter half of 20th century Roy [2010, 2013] also detected such signal in observation. Interestingly, when the focus is on period A and B, column II, it is clear that the NAO solar relationship not only weakened but sometimes reversed in sign. Gray et al. [2013, Fig $3,4]$ using data from longer period found an opposite association between the sun and NAO in zero lag case. Furthermore, Roy and Haigh [2010, Fig 1] also detected similar features for longer period. In both those studies, sun and NAO suggested a negative (insignificant) association, matching to that of Period B, Table 1. However, such opposing nature of sun and NAO though was shown in various highly cited papers, but to my knowledge, it was never discussed before. Such observation raises doubt about the study of Ineson et al. [2011]. According to them, in years of low solar activity, it always suggests the negative phase of NAO. The opposite mechanism is true when solar activity is higher than usual, indicating a positive phase of NAO. The current analyses however questions the robustness of the association between the sun and NAO (Ineson et al. 2011). Such understanding is a major step forward of climate studies. It indicates that the mean atmospheric state also needs to be taken into account with additional care in detecting the role of the sun on major climate variability 
and proposing a mechanism based on any detected signals. ENSO, however, does not show any significant influence on NAO in any of the periods.

Influence of ENSO (column III):

Now the attention is on the major dominant variability in tropics, the ENSO and it is interesting to identify whether ENSO is also influenced by other dominant factors. Here possible candidates considered are longer term trend, to represent a linear rise in temperature, which is associated with anthropogenic influence and natural variability represented by volcanic eruptions and SSN. The discussion mainly follows on ENSO and natural variability.

In column III, the results using ENSO as the dependent parameter is presented. One interesting finding from column III is the role of volcanic eruptions on ENSO. A volcanic eruption is seen to favour positive phase of ENSO strongly, but only true during last half of the 20th century. The signal is strongest during period D (99\% significant), while it is weak in period B. Such result during period B (1856-1957) is probably dominated by lesser/weaker volcanos during the first half of the 20th century. During that half, without many volcanic eruptions, ENSO still followed its inter-annual variability. When considering the overall period of analysis in period A, volcano and ENSO relationship is found to be dominated by period D and suggests a level of significance up to $95 \%$. Such analysis is consistent with various works as discussed earlier [Emily-Geay et al., 2008; McGregor et al., 2011; and Adams et al., 2003] that showed ENSO is noticeably influenced (in preference of its positive phase) by active volcanic eruptions. It is also consistent with the observation of Fig. 1 (ii), bottom panel and explains why SST trend along the equator in the final 50 years of the 20th century shows a robust El Niño-like pattern for all observations using different datasets [Liu et al., 2005].

There are also some modelling works those support ENSO, volcano connections. Ohba et al., (2013) studied the effect of super volcanic eruption in Model for Interdisciplinary Research on Climate (MIROC5). It suggested about excitation of the anomalous west Pacific westerly which subsequently causes an increase in the probability of El Niño. It agrees with observational data of longer-term paleoclimate records (Adams et al. 2003, McGregor et al. 2011). A similar response is also noticed by Stenchikov et al. (2009) that used Geophysical Fluid Dynamics Laboratory (GFDL) CM2.1 model. The model result of Ohba et al. (2013) suggests that explosive volcanos during El Niño phase contribute to the duration of El Niño, whereas the same during La Niña phase counteract to its duration. Thus, the period of La Niña shortens. The effect of strong volcanos on El Niño is more substantial than that in La Niña due to the amplification by the air-sea coupled feedback [Stenchikov et al., 2009].

A little discussion can be added here about possible mechanisms relating to the ENSO and volcano connection. Warming in the central equatorial Pacific in response to explosive volcanos (Table 1, column III) can be explained by a hypothesis known as the dynamical thermostat hypothesis (Clement et al. 1996). It states for a uniform reduction of incoming surface solar radiation to a great extent, (which is associated here with explosive volcanos) the response of SST is different on two sides of the tropical Pacific. Due to ocean advection theory, the western Pacific cools faster than the east. It initially reduces the climatological zonal SST gradient, which subsequently influences trade winds in the central Pacific. The resultant positive SST gradient can activate El Nino phase reversing trade winds. McGregor et al. (2011) proposed another theory that states, the anomalous westerly in tropical Pacific could be attributed to the rapid response over the maritime continent, in response to uniform reduction of incoming surface solar radiation. It is mainly linked to the land-sea contrast, where the surface cooling around equatorial Pacific and its time-scale for adjustment are leading responsible factor. It is the fast cooling around the maritime continent that contribute to the positive zonal SST gradient. However, the role of a dynamical thermostat (Clement et al. 1996) and the proposition of McGregor et al. (2011) both can act together to reinforce the mechanism relating to volcano and ENSO.

Another interesting finding from column III is about solar-ENSO behaviour. In period C, there is a positive solar signal detected in ENSO, which is only significant up to $80 \%$ level. Though it is 
less significant the sign of such signature is in agreement with White et al. [1997, Fig 6, Top] who using data of second half of the 20th century detected a similar in-phase relationship between the sun and ENSO. However, when the focus is on Period B, the relationship not only reversed but even showed significance up to $95 \%$ level. It is noteworthy that Roy and Haigh [2012], focusing on a similar period of analysis, also observed the preferential alignment of the negative phase of ENSO during active phases of the solar cycle (i.e., when SSN >80) during northern winter. Considering spatial pattern, Roy [2010, 2013] however could not identify a detectable signature in tropical Pacific Sea Surface Temperature (SST) using Hadley Sea Surface Temperature version 2 (HadSST2) data during the same period, possibly because that accounted every month of the year rather than only boreal winter. Van Loon et al. [2007] and Meehl et al. [2008] using the method of a solar peak year compositing detected similarly signed signature during December January February (DJF), though it only focused on peak solar years rather than active/inactive phases of the solar cycle. Due to two opposite nature of signature in period B and C, it is difficult to discern any solar-ENSO relationship for the entire period of analysis as also noted in period $\mathrm{A}$.

During an earlier period (DJF), the significant negative association between the sun and ENSO can be explained by the hypothesis of a dynamical thermostat (Clement et al. 1996) and the proposition of McGregor et al. (2011). Interestingly, during inactive phase of the sun, there is a uniform reduction of surface heat fluxes, and hence, the same principle as discussed for the volcano is equally applicable. It could trigger El Niño like situation, while active solar years will trigger La Niña like situation following reverse mechanism. The decadal solar signature for inciting trade wind is clearly detected in Fig. 2a (left) (and discussed in section 3.2), which is though small in magnitude, but significant up to $95 \%$ level. Such association is also seen in Table 1, Period B, column III, as reflected by sun ENSO connection ( $\beta=-0.84$, significant at $95 \%$ level). In general, such analysis indicates that solar cycle drives the coupled ocean-atmosphere system more subtly towards a state in which La Niña conditions are often favoured for active solar years. Whereas, El Niño s are usually favoured for low solar years. It is noteworthy that the sun ENSO connection was reverted again like earlier period since 1998 (Roy, 2013, Roy and Haigh, 2012). The ENSO suggested cold phase not only during peak solar years of active cycles, but that also followed 1 to 2 years after the peak. Overruling all speculations, the last solar peak year of 2014 again suggested the cold phase of ENSO (Roy et al. 2016).

(a) Solar
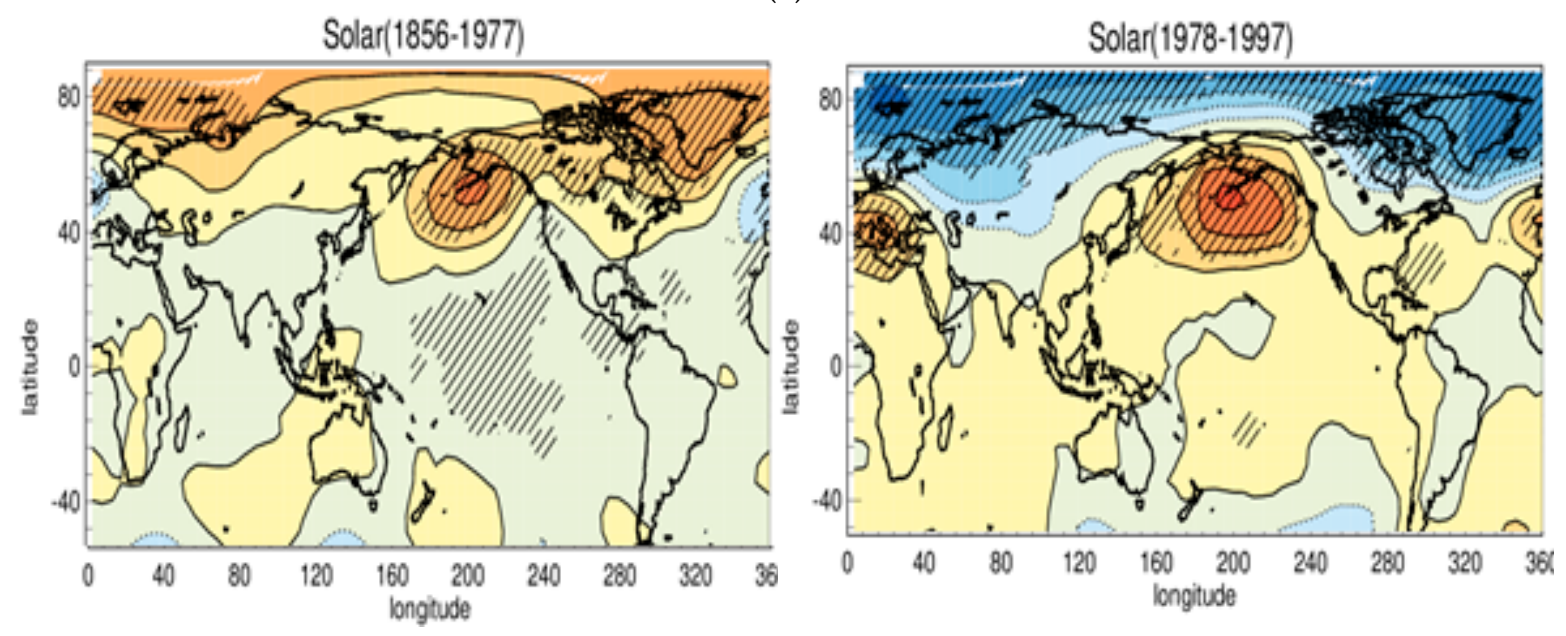

(b) ENSO

ENSO(1856-1977)

ENSO(1978-1997) 


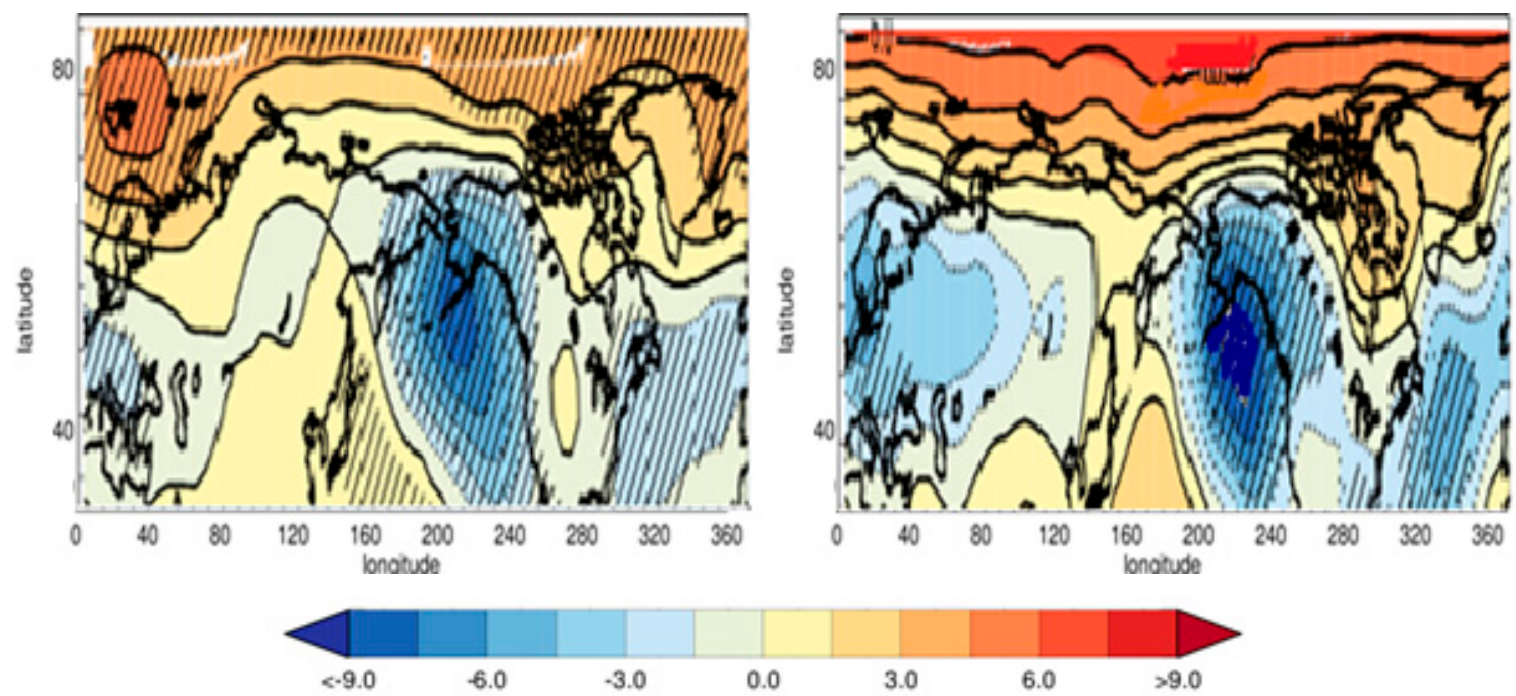

Fig. 2: Amplitudes of the components of variability for SLP (in hPa) during DJF. The top panel (a) is due to SSN using different independent factors as longer term trend, AOD and ENSO; whereas, bottom panel (b) is due to ENSO using independent factors as the trend, AOD and SSN. The right panel is for the period (1978-1997) and the left panel for (1856-1977). Shaded regions are estimated significant at the $95 \%$ level using a t-test.

\subsection{Identifying spatial signature:}

Focusing attention on the spatial pattern, an MLR technique is applied on SLP with independent parameters as AOD, linear trend, ENSO, and SSN. Shaded regions are estimated significant at the 95\% level using a t-test. The major findings are now discussed below.

\subsubsection{Signature due to the Sun:}

Fig. 2a shows solar signature in SLP (spatial pattern) excluding other major factors (volcano, ENSO, and trend), those are very likely to influence results. The right panel is for 1978-1997; whereas, left panel for the earlier period of available data series. In both the figures (Fig. 2a), a strong positive signal around Aleutian Low (AL) is clearly detected suggesting the robustness of that signal as noticed by Roy and Haigh [2010]. Right panel of Fig. 2a suggests a positive Arctic Oscillation (AO) pattern; whereas, a clear dissimilarity is noticed around the far North Atlantic in the left panel. A positive NAO-like signature is clearly distinguished in the right panel which is in agreement with the results of Table-1 (Period D, column II) and the study of Ineson et al. [2011]. Surprisingly, that signature is opposite in nature in the left panel (Fig. 2a) with significant region mainly localised around the places of Greenland. Such opposite signature is also noticed in Roy [2010, 2013], that used earlier and latter periods of observational data. In those two works, however, it did not discuss solar NAO connections, neither did it consider/compare various time periods over 150 years. Current analyses also explain why Roy and Haigh [2010, Fig 1] could not identify any NAO-like pattern using data of longer time period as is also seen and discussed in Table 1, (Period A, column II). All such analyses raise doubt about any proposed relationship as discussed in Ineson et al. [2011] and other related studies based on similar mechanism. It indicates that the robustness of solar NAO known connection needs to be explored further, and it could be a step forward for the climate community.

A brief discussion is presented on mechanism relating to the Sun and NAO connection, which can be explained by a mechanism proposed by Bjerknes (Bjerknes 1966) relating to tropical Pacific and mid-latitudes. Bjerknes (1966) showed that the major warming along the central and equatorial Pacific during boreal winter is often accompanied by an anomalous strength of the midlatitude westerlies. The anomalously great heat from the equatorial ocean to the rising branch of the Hadley circulation would strengthen the cell. It will generate above normal flux of angular momentum to the westerly winds around midlatitude belt. Thus, warming in the tropical Pacific can strengthen the midlatitude westerly jets during boreal winter and subsequently can favour positive phase of the 
NAO. During latter decades, the broader maxima of solar cycles (1-2 year after peak solar years) are inclined to warm events of ENSO (Roy and Haigh, 2012, Roy 2013). The anomalously great heat of warm equatorial ocean enters into the rising branch of the Hadley circulation and subsequently can favour positive phase of NAO. Such response is strongest in the winter hemisphere due to greater baroclinicity. During the earlier period (DJF), the sun showed preferences towards La Niña phases (Roy and Haigh, 2012, also Table 1, Column III) in all active solar years. Due to the similar mechanism (Bjerknes 1966), it will suggest a weakening of mid-latitude westerlies in boreal winter, indicating a negative association between the sun and NAO (Fig. 2a, left).

In Fig. 2a, the solar signal around tropical Pacific is also seen to be different in the left panel to that from the right. In the left panel, the significant signal observed in the tropics (though small in amplitude but $95 \%$ significant) might be responsible to incite trade wind and thus can favour cold event like situations of ENSO via indirect dynamical coupling (Roy, 2013). Such signature is missing in the right panel, which suggests it might be one of the several factors that could also be responsible for different sun and ENSO connection, positive during the 2nd half of 20th century to that of the earlier period of the data, which is negative and significant up to $95 \%$ level (Table, 1, period B, column III). It supports the hypothesis of a dynamical thermostat (Clement et al. 1996) and the proposition of McGregor et al. (2011) as discussed in section 3.2 in connection with the sun and ENSO, involving anomalous westerly in the tropical Pacific.

\subsubsection{Signature due to the ENSO:}

Fig. $2 \mathrm{~b}$ shows the spatial signature of ENSO on SLP using MLR, excluding SSN, AOD, and linear trend. The right-hand panel is for 1978-1997 and left hand for 1856-1977. Both the panels of Fig. 2b identifies negative NAO pattern for ENSO around the polar region. For solar signature (Fig. 2a), tropical Pacific trade wind was involved and hence the plot that covered tropical Pacific was shown. However, for ENSO signature, the focus of present discussion is mainly around polar region of $\mathrm{NH}$ and hence only parts of the northern hemisphere is displayed (Fig. 2b). The positive phase of ENSO is responsible for the warming of polar vortex during northern winter, as detected in observation [Thompson, Baldwin and Wallace, 2002] and model [Toniazzo and Scaife, [2006]]. It subsequently suggests a negative phase of polar annular modes in troposphere [Baldwin and Dunkerton, 2001]. One possible route how the ENSO influences polar vortex and then down to Arctic region can be through well-known Brewer-Dobson circulation. Significant signature is noticed around the polar region in Fig. 2b left-panel, but missing in the right panel. Variability of SLP is however increased in the polar area of Fig. $2 b$, right panel. It might be the effect of a change in the mean state due to combined different influence of active volcanos and sun around the place of polar vortex during the later period. Such changes in ENSO around the polar region of troposphere might be related to a mode of ENSO, as detected by Yeo and Kim [2013] that exhibit a clear trend representing global SST warming with an 'El Niño-like' pattern having a strong opposite signature around polar region. It might also be linked to the fact that unevenly high number of warm events occurred to that from cold events during the period 1978-1997, as discussed earlier.

All these studies indicate that due to change in mean state of the atmosphere, the influence of major climate factors is felt differently in different parts of the globe.

\subsection{Addressing the polar vortex Mechanism:}

Here is a brief discussion about mechanism mainly involving polar vortex. During active solar years, the stratospheric polar jet is strengthened following well-known mechanism (thermal wind balance relationship) as discussed earlier. Planetary waves propagating upward cannot propagate through very strong stratospheric polar jet following Charney-Drazen criteria. Kodera and Kuroda, (2002) proposed a possible mechanism whereby the solar heating anomalies that change the strength of polar stratospheric jet can influence the path of upward propagating planetary waves. These waves, deposit their zonal momentum on the poleward side of the jet, as those can not pass through very strong stratospheric polar jet (Charney-Drazen criteria) and thus warm the stratospheric pole. It subsequently weakens the Brewer-Dobson circulation and as a consequence warms the tropical 
lower stratosphere in solar maximum compared with solar minimum periods. However, the current study only focuses on the polar stratosphere. The perturbations around polar stratosphere can influence troposphere [Baldwin and Dunkerton, 2001]. Thus warming on the poleward side of the stratospheric jet will indicate negative NAO feature in the surface ((Fig. 2a, left panel), Roy [2013]; Gray et al, [2013, Fig 3, 4, for zero lag case].

Let now discuss the connection between NAO and major volcanos involving polar vortex. Active volcanos are responsible for substantial ozone destruction in the stratosphere [Robock, 2003]. Reduced ozone with less UV warming could be one responsible factor for reduced temperature contrast between winter hemisphere to that from summer. It subsequently via thermal wind balance relationship can weaken the strength of winter stratospheric polar jet. Upward propagating planetary waves can propagate through that weak jet as discussed for Charney Drazen criteria. Thus, active volcano years are likely to have undisturbed, cold polar vortex and the signature around troposphere [Baldwin and Dunkerton, 2001] suggests positive NAO features. The effect of the volcano is seen to produce positive NAO feature as shown by Gray et al. [2013, Fig. 3] and Roy et al 2016. They considered nearly 150 years period and used MLR technique. Such study is also consistent with the observation in Table 1 for period A, column II. The large volcanic eruptions have a tendency to induce a positive NAO response is also shown in various studies [Cui et al. [2014], Wang et al. [2012]]. It also agrees with the work of Robock and Mao, [1992] and Driscoll et al. [2012], who detected significant surface warming over the continents in the $\mathrm{NH}$, especially around northern Europe and Asia during post-volcanic winter, which is usually linked with the positive phase of NAO.

Now we discuss how the sun and NAO relationship has changed. The last two solar cycles of the 20th century suggest that solar signal resembles that of the positive phase of NAO (Fig, 2a and Table 1, column II, period D). It might be due to combining opposite influence of active volcanos and sun around the place of the polar vortex. As volcano changes the mean state of the stratosphere (that involves ozone), it is likely to cause weakening of the general strength of stratospheric polar jet during active solar years. Planetary waves can propagate through that weak jet generating undisturbed and cold polar vortex. The tropospheric surface signature of the sun thus suggests positive NAO pattern during that period.

\subsection{Question on Sun NAO lag relationship:}

A recent study by Gray et al. [2013] and Scaife et al. [2013] noted solar lag relationship around places of the Azores high and discussed mechanism based on their results. Here, MLR technique is applied during same two different time periods as considered in Fig. 2 and solar lag relationship (lag year 1 to lag year 3, Fig.3a-c) is performed. The results are also compared with the overall 150 years of data (in the bottom panel of each figure) as is done in Gray et al. [2013].

\section{a) Lag1:}
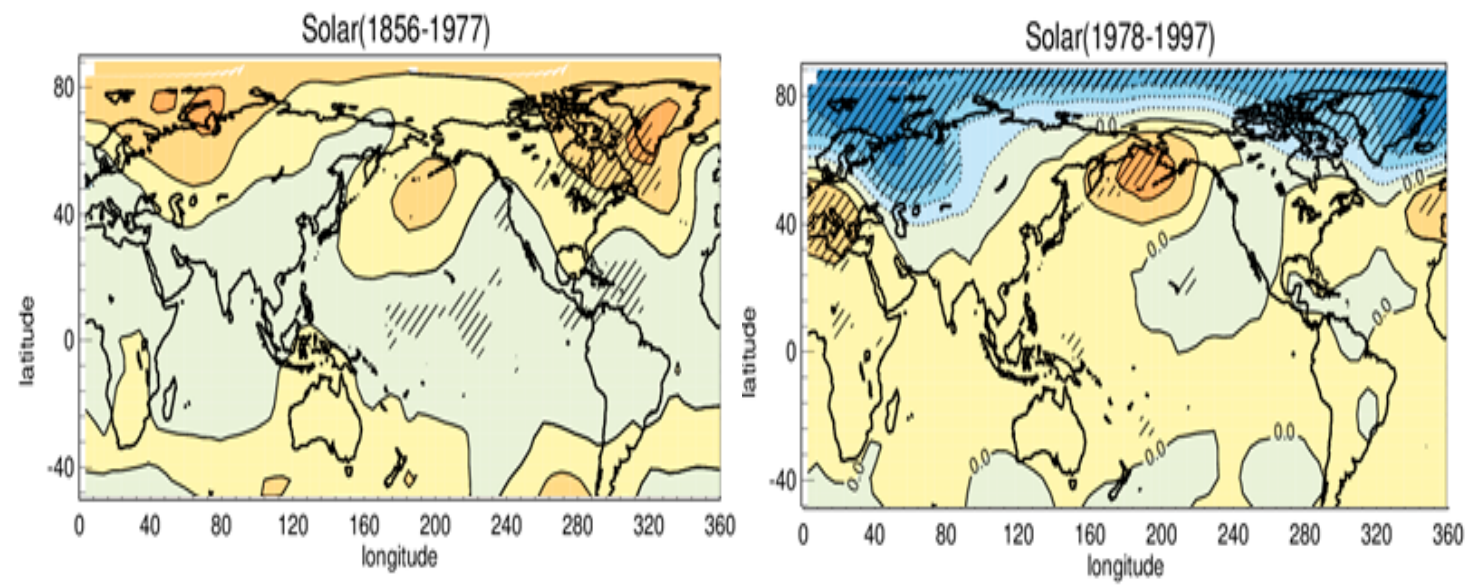

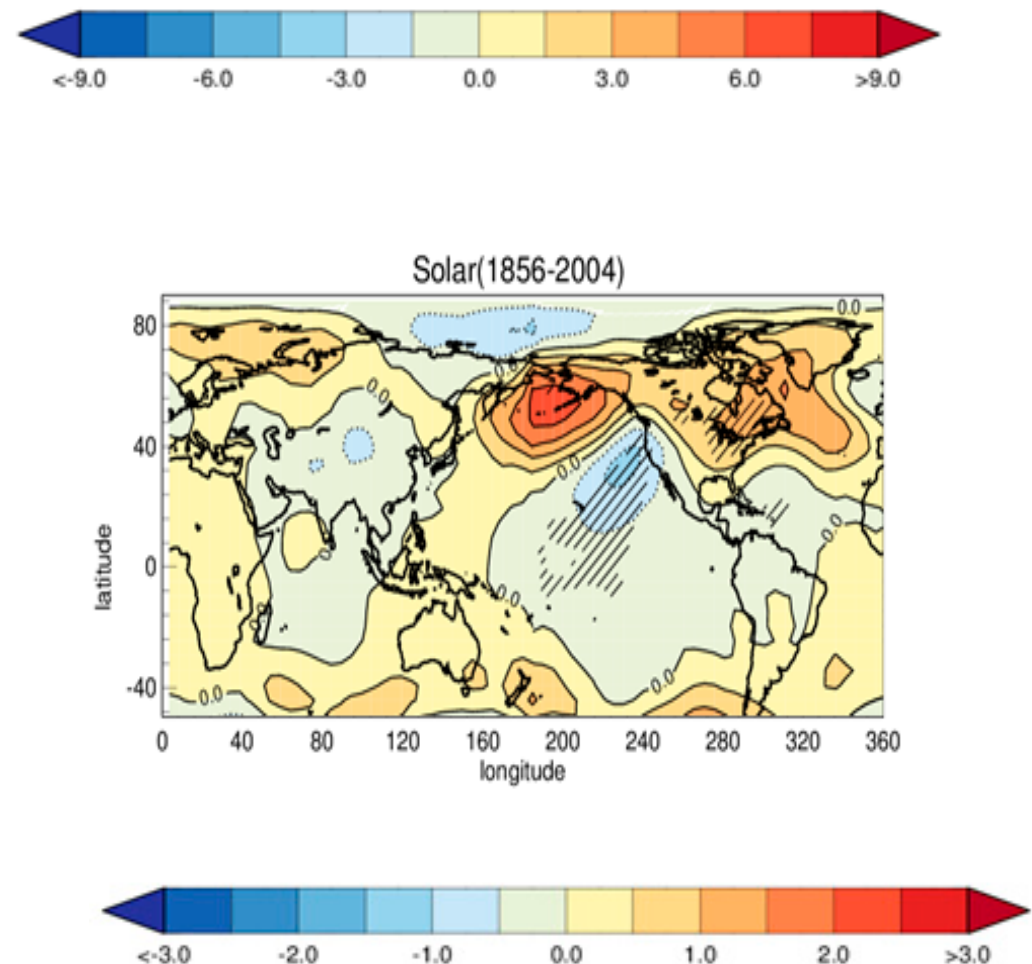

b) Lag 2:
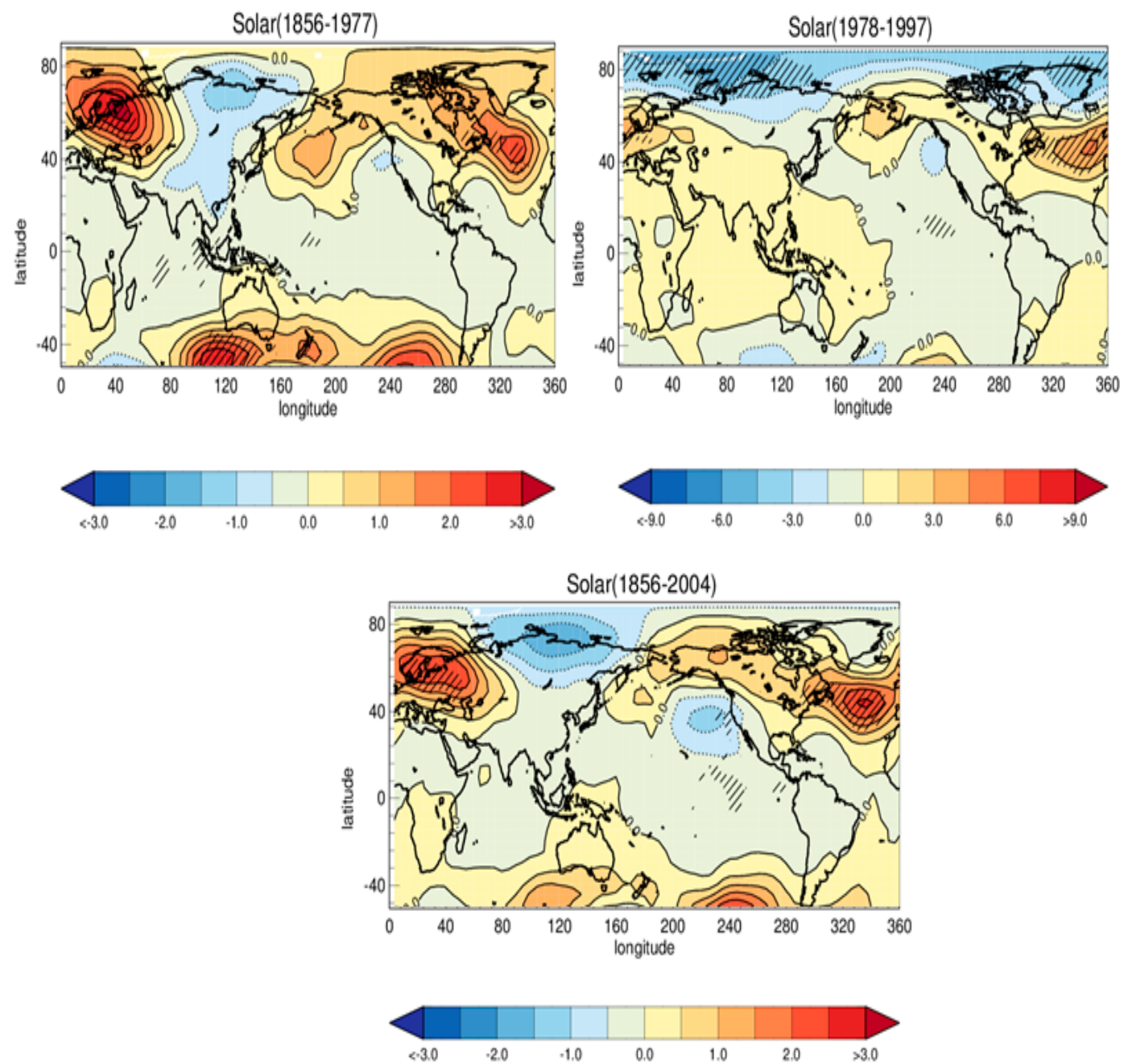


\section{c) Lag 3:}
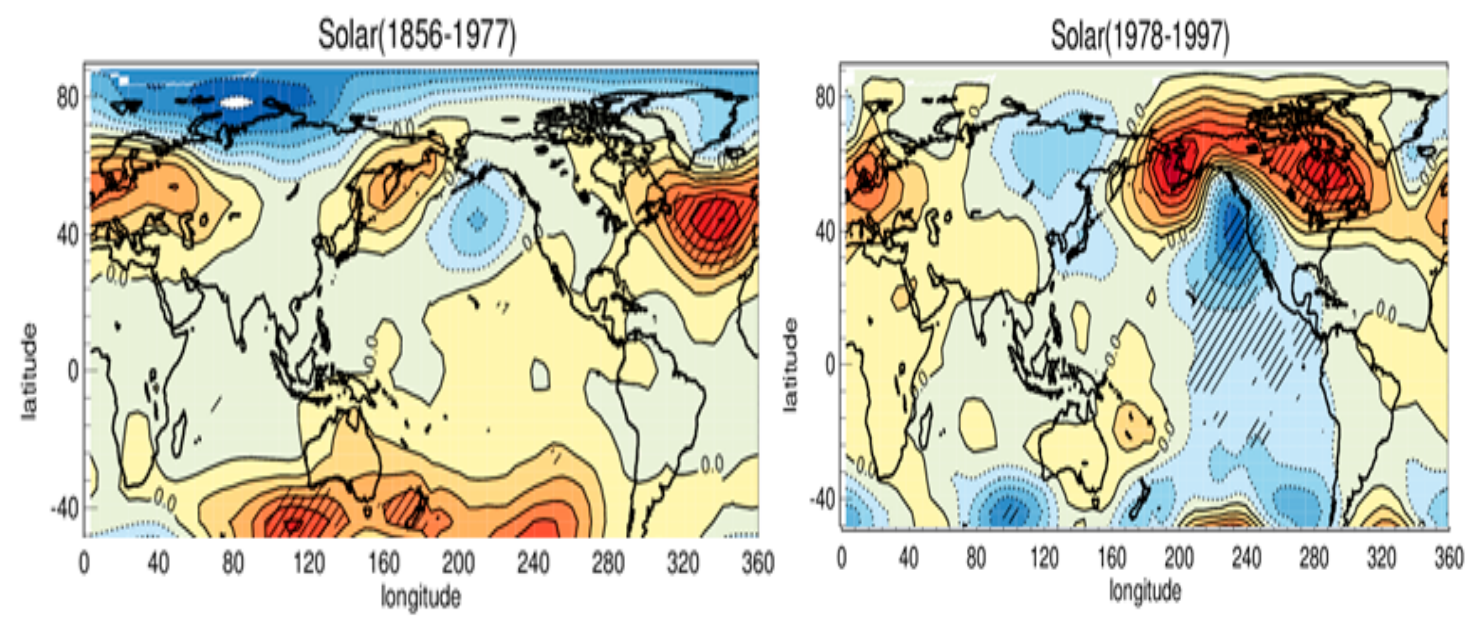

Fig. 3: Amplitudes of the components of variability for SLP due to solar cycle variability (max-min), in $\mathrm{hPa}$ during DJF for a) lag of one year, b) lag of two years and c) lag of three years. Independent factors used are longer term trend, AOD and ENSO. Shaded regions are estimated significant at the 95\% level using a t-test.

Fig. 3a shows results for lag year 1 . The top two figures show a clear difference between the north pole which are similar in nature like Fig.2a respectively, though much weaker here. Signature in Fig. 3a, bottom panel, matches to that of the top left panel in places of North Atlantic probably due to longer data records of the earlier period. The result of the bottom panel is similar to that of Gray et al. [2013].

Fig $3 \mathrm{~b}$ and c are for lag year 2 and 3 respectively. North Atlantic region in lag year 2 (Fig, 3b), the bottom panel is dominated by strong signal during the period 1978-1997; whereas, for Fig. 3c it is overpowered by an earlier period (1856-1977). Strong positive solar signature for 150 years record is around Azores high for lag year 2 and 3 (strongest for lag year 3) which is consistent with the study by Gray et al. [2013]. The main findings in Fig. 3, bottom panel concerning longer record is in agreement with Gray et al. [2013]. The little deviation, if noticed, might be related to a slight difference in the period considered.

The main observation from these analyses is that the lag relationship is also not robust and sensitive to the period chosen. The result of the overall time is mainly dominated by a period that has stronger signals. Hence, caution should be taken in proposing any mechanism based on any detected signal unless that signal is very robust. It also points towards the complexity in relating major variabilities like a solar 11-year cycle, ENSO, and NAO without taking proper account of active volcanic eruptions and related dynamical coupling.

There could be an argument about the SLP data qualities. However, in support of robustness of current analyses, it may be stated that various popular highly cited research used the same data around polar region. That include those papers that we compared here [Ineson et al., (2011); Van Loon et al. (2007) and Gray et al. (2013), etc.].

\section{Discussion and Summary}

The NAO mainly explains the variability of CET, and this is right irrespective of chosen periods of reference (shown here in Table 1, column I). However, NAO is influenced by other factors differently at different times (Table 1 , column II).

The current study shows that the last two solar cycles of previous century suggest a strong positive connection between the volcanic eruptions and ENSO (Table 1, column III). Other modelling 
and observational results also support such connection (Ohba et al., 2013; Adams et al. 2003; McGregor et al. 2011; Stenchikov et al., 2009). In the current study, we did not have the scope to confirm but elaborately discussed some well-known theory in support of mechanism. Those are dynamical thermostat hypothesis (Clement et al. 1996), and the theory by McGregor et al. (2011) that links land-sea contrast. Both can indicate about mechanism relating to volcano and ENSO as observed. That two hypothesis can also act together to reinforce the mechanism.

The present work also confirms that prior to climate change period (1856-1957), a significant inverse relationship between the SSN and ENSO is identified during DJF. The signal is even opposite in sign and less significant during the second half of 20th century (shown in Table 1, column III). The hypothesis of a dynamical thermostat (Clement et al. 1996) and the proposition of McGregor et al. (2011) can also explain cooling in the central tropical Pacific during an earlier period, which is mainly related to more solar radiative forcing in active solar years. However, in the current work, that widely known hypothesis and proposition were only discussed and not tested.

It is also seen in the observation that explosive volcanos are often associated with the positive phase of NAO (presented in Table 1, Period A). It thus agrees with winter polar warming (Robock and Mao, 1992). Bjerknes proposed (Bjerknes 1966) an important mechanism that can explain such association. As it is a widely known feature, we only discuss without confirming that here. The anomalously great heat from the equatorial ocean (related to ENSO due to the volcano) to the rising branch of the Hadley circulation would strengthen the cell generating above normal flux of angular momentum to the westerly winds around mid-latitude. Following such non-linear alignment, volcano indicates a positive association with NAO. Such feedback loop is responsible for reinforcing the signals that are also linked with polar vortex mechanism as discussed earlier.

The positive relationship between the NAO and the sun as identified by other studies, though observed during last two decades of 20th century, missing in earlier periods (Table 1, column II and Fig. 2a). The connection is strongest during later decades (Table 1, period D and Fig. 2a) when explosive volcanos coincidentally matched with the active phase of solar cycles. Those are confirmed by the current study; however, the explanation in support which can be provided by well known Bjerknes mechanism (Bjerknes 1966) linking tropical Pacific and midlatitude is only discussed here. During latter decades, the broader maxima of solar cycles (1-2 year after peak solar years) are inclined to warm events of ENSO (Roy and Haigh, 2012, Roy 2013). Such warming via Hadley cell is often accompanied by strengthening the midlatitude westerlies and subsequently, responsible for positive sun NAO connection. Following similar mechanism, active sun and cold ENSO, as it the case for the earlier period, will suggest a weakening of midlatitude westerlies in boreal winter, indicating a negative association between the sun and NAO (as presented here in Fig. 2a, left). It also reinforces the mechanism that involves the polar vortex.

Apart from raising issues concerning the robustness of earlier proposed connection on the Sun and NAO, it also questioned on their lag relationship. The current study clearly demonstrated that the lagged correlation proposed by Gray et al. (2013) and widely accepted finding of positive $\mathrm{NAO} /$ solar activity correlations are not stationary and robust.

As massive volcanic eruption that coincides with peak years of active solar cycles (unlike other volcanos of the century) can have an enormous impact on the mean state of the atmosphere, that includes the stratosphere as well as ocean and thus solar, NAO and ENSO relationship needs to be investigated with additional care. Understanding the role of natural factors and their interactions with major variability regionally as well as seasonally is crucial to pinpoint the effect of human influence, which is essential to improve model performance and future prediction skill.

Acknowledgements: This work was motivated by third-year undergraduate project supervision in the University of Exeter, 2012 with project title 'Factors affecting winter temperature around Europe' with codes 'ECM3735'. The author is grateful to Prof Mat Collins, the University of Exeter for useful discussion. 


\section{References}

Adams, J. B. Mann M. E. and Ammann C. M. et. al. (2003), Proxy evidence for an El Niño-like response to volcanic forcing, Nature, 426. doi:10.1038/nature02101.

Allan, R.J. (2000), ENSO and climate variability in the last 150 years, in El Niño and the Southern Oscillation: multiscale variability, global and regional impacts, edited by H.F. Diaz and V. Markgraf, pp. 3-55, Cambridge Univ. Press, New York.

Baldwin, M.P. and Dunkerton, T.J. (2001), Stratospheric harbingers of anomalous weather regimes. Science, 294, 5542, 581-584, DOI: 10.1126/science.1063315.

Bjerknes, J. (1966), A possible response of the atmospheric Hadley circulation to equatorial anomalies of ocean temperature, Tellus, 18, 4, 820-829, DOI: 10.1111/j.2153-3490.1966.tb00303.x

Bond N. A, J. E. Overland, M. Spillane and P. Stabeno (2003), Recent shifts in the state of the North Pacific. Geophys. Res. Lett., 30(23), 2183, doi:10.1029/2003GL018597.

Clement A.C, Seager R, Cane M. A, and Zebiak, S.E, (1996), An Ocean Dynamical Thermostat. J. Climate, 9, 2190-2196. doi: http://dx.doi.org/10.1175/1520-0442

Compo, G. P., J. S. Whitaker, P. D. Sardeshmukh, N. Matsui et al. (2011), The twentieth century reanalysis project, Q. J. R. Meteorol. Soc., 137 (654), 1-28, doi: 10.1002/qj.776.

Driscoll S, A Bozzo, Gray L J and Robock A et al. (2012), Coupled Model Inter-comparison Project 5 (CMIP5) Simulations of Climate Following Volcanic Eruptions. Journal of Geophysical Research,117, D17, DOI: 10.1029/2012JD017607.

Emile-Geay J., R. Seager, M.A. Cane, E. R. Cook, and G.H. Haug, (2008): Volcanoes and ENSO over the Past Millennium. J. Climate, 21, 3134-3148.

Fedorov, A. and Philander S. G. (2000), Is El Niño Changing? Science. 288, 5473, pp. 1997-2002. DOI: 10.1126/science.288.5473.1997.

Gray, L.J., J. Beer and M. Geller, et al. (2010), Solar influences on climate. Rev. Geophys., 48, RG4001, doi: 10.1029/2009RG000282.

Gray, L.J., Scaife, AA and Mitchell, D.M et al. (2013), A lagged response to the 11 year solar cycle in observed winter Atlantic/ European weather patterns. Journal of Geophysical Research: Atmospheres, 118, 13,40513,420, doi: 10.1002/2013JD020062.

Gu D, Philander S. G. (1997), Inter-decadal climate fluctuations that depend on exchanges between the tropics and extra-tropics. Science 275 (5301):805-807.

Haam, E. and Tung, KK. (2012), Statistics of Solar Cycle-La Niña Connection: Correlation of Two Autocorrelated Time Series, Journal of the Atmospheric Sciences, 69, 2934-2939.

Haigh, J. D. (1996), The impact of solar variability on climate, Science, 272(5264), 981-984.

Haigh, J. D., Blackburn, M., and Day, R. (2005), The response of tropospheric circulation to perturbations in lower-stratospheric temperature, J. Climate, 18 (17), 3672-3685.

Hansen, J., R. Ruedy, M. Sato, and K. Lo (2010), Global surface temperature change, Rev. Geophys., 48, RG4004, doi:10.1029/2010RG000345.

Iles C. E., Hegerl G. C, Schurer A.P. and Zhang X., (2013), The effect of volcanic eruptions on global precipitation. Journal of Geophysical Research Atmospheres, 118, 16, 8770-8786.

Ineson S. , Scaife A. A., Knight, J. R. et al. (2011), Solar forcing of winter climate variability in the Northern Hemisphere, Nature Geoscience, 753-757, DOI: 10.1038/NGEO1282.

Ingleby, N. B. (2001): Comments on "A statistical determination of the random observational errors present in voluntary observing ships' meteorological reports", J. Atmos \& Oceanic Tech., 18, 1102-1107.

IPCC, Climate Change (2013), The Physical Science Basis. Contribution of Working Group I to the Fifth Assessment Report of the Intergovernmental Panel on Climate Change, Cambridge University Press, Cambridge, U.K.; New York, U.S.A. http://www.climatechange2013.org/images/report/WG1AR5_ALL_FINAL.pdf

Jones, P.D. Jonsson, T and Wheeler, D (1997), Extension of the North Atlantic Oscillation using early instrumental pressure observations from Gibraltar and southwest Iceland, Int. J. Climatol. 17:1433-1450.

Kaplan, A., Cane M., Kushnir Y., Clement A., Blumenthal M., and Rajagopalan B. (1998), Analyses of global sea surface temperature 1856-1991, J. of Geophys. Res., 103, 18,567-18,589.

Kent, E. C., and P. K. Taylor, (1997): Choice of a Beaufort Equivalent Scale. J. Atmos. Oceanic Technol.,14, 228242.

Kiehl, J.T., Kevin E. Trenberth. (1997), Earth's annual global mean energy budget. Bulletin of the American Meteorological Society 78 (2),197-208. 
Kodera, K. and Kuroda, Y (2002), Dynamical response to the solar cycle. J. Geophys. Res., 107, D24, 4749, doi:10.1029/2002JD002224.

Latif M, Kleeman R, Eckert C. (1997), Greenhouse warming, decadal variability, or El Niño? An attempt to understand the anomalous 1990s. J. Climate, 10 (9):2221-2239.

Lean, J. and Rind, D. (2001): Earth's response to a variable Sun, Science, 292, 5515, 234-236.

Liu Z., S. Vavrus, F He, N. Wen, and Y. Zhong (2005), Rethinking Tropical Ocean Response to Global Warming: The Enhanced Equatorial Warming. J. Climate, 18, 4684-4700.doi: http://dx.doi.org/10.1175/JCLI3579.1.

Manley,G. (1974), Central England Temperatures: monthly means 1659 to 1973. Q.J.R. Meteorol. Soc., Vol 100, pp 389-405.

McGregor, S., A. Timmermann, and O. Timm, (2010): A unifiedproxy for ENSO and PDO variability since 1650. Climate Past, 5, 1-17.

McGregor, S and A. Timmermann, (2011), The Effect of Explosive Tropical Volcanism on ENSO, J. Climate, 24, 2178-2191. doi: http://dx.doi.org/10.1175/2010JCLI3990.1

McPhaden, M. J, and Zhang, D., (2004): Pacific Ocean circulation rebounds, Geophys. Res. Lett., 31, L18301, doi:10.1029/2004GL020727.

Meehl, G. A. and Teng, H. (2014), CMIP5 multi-model hindcasts for the mid-1970s shift and early 2000s hiatus and predictions for 2016-2035 Geophysical Research Letters. 41, Issue 5, 1711-1716.

Meehl, G. A., J.M. Arblaster, G. Branstator, and H. van Loon, (2008), A coupled air-sea response mechanism to solar forcing in the Pacific region, J. Climate, 21(12), 2883-2897.

Meehl, G. A., Arblaster, J. M., Matthes, K., Sassi, F., and van Loon, H. (2009): Amplifying the Pacific Climate System Response to a Small 11-Year Solar Cycle Forcing. Science, 325,1114-1118, doi:10.1126/science.117287.

Mitchell, D. M., L. J. Gray, and A. J. Charlton-Perez, (2011), The structure and evolution of the stratospheric vortex in response to natural forcings, J. Geophys. Res., 116 (D15), doi:10.1029/2011JD015788.

Miller J., D. R., Cayan, T. P. Barnett, N. E. Graham and J. M. Oberhuber (1994), The 1976-77 climate shift of the Pacific Ocean. Oceanography, 7, 1.

Pierce DW, Barnett TP, Latif M. (2000), Connections between the Pacific Ocean tropics and midlatitudes on decadal timescales. J Climate 13 (6):1173-1194.

Minobe, S., (2000), Spatio-Temporal Structure of the pentadecadal variability over the North Pacific. Prog.in Oceanogr., 47, 381-408,

Nguyen, H., C. Lucas, I. Smith, and B. Timbal, (2013), The Hadley circulation in reanalyses: Climatology, variability, and change, J. Climate, 26(10), 3357-3376.

Ohba M, H. Shiogama, T Yokohata and M Watanabe, (2013), Impact of Strong Tropical Volcanic Eruptions on ENSO Simulated in a Coupled GCM, American Meteorological Society, 26, 5169- 5182, DOI: 10.1175/JCLI-D-12-00471.1

Parker, D.E., T.P. Legg, and C.K. Folland. 1992. A new daily Central England Temperature Series, 1772-1991. Int. J. Clim., Vol 12, pp 317-342.

Parker, D.E. and Horton, E.B. 2005. Uncertainties in the Central England Temperature series since 1878 and some changes to the maximum and minimum series. International J.Climatology, Vol 25, pp 1173-1188.

Qiong, Z, Yue G. and Haijun, Y (2008), ENSO Amplitude Change in Observation and Coupled Models, Advances in Atmospheric Sciences, 25, 3, 361-366.

Robock, A., and J. Mao, (1992), Winter warming from large volcanic eruptions, Geophys. Res. Lett., 19 (24), 2405 2408, doi: 10.1029/92GL02627.

Robock, A. (2003),Volcanoes: Role in climate. in Encyclopedia of Atmospheric Sciences, J. Holton, J. A. Curry, and J. Pyle, Eds., (Academic Press, London), 10.1006/rwas.2002.0169, 2494-2500. (Invited paper).

Roy, I. (2010), Solar signals in Sea Level Pressure and Sea Surface Temperature, Ph.D. Thesis, Department of Space and atmospheric Science, Imperial College London.

Roy, I. (2013), The Role of the sun in Atmosphere Ocean Coupling. International Journal of Climatology, doi:10.1002/joc.3713.

Roy and Collins, (2014) On identifying the role of Sun and the El Niño Southern Oscillation on Indian Summer Monsoon Rainfall, Atmos. Sci. Let. DOI: 10.1002/asl2.547

Roy, I. and J. D. Haigh, (2010), Solar cycle signals in sea level pressure and sea surface temperature, Atmos. Chem. Phys., 10, 6, 3147-3153. 
Roy, I. and J. D. Haigh. (2011), The influence of solar variability and the quasi-biennial oscillation on lower atmospheric temperatures and sea level pressure, Atmos. Chem. Phys., 11, 11679-11687, doi: 10.5194/acp-1111679-2011.

Roy, I. and J.D. Haigh, (2012), Solar Cycle Signals in the Pacific and the Issue of Timings. Journal of Atmospheric Science, 69, 4, 1446-1451, doi: http://dx.doi.org/10.1175/JAS-D-11-0277.1.

Roy, I, T. Asikainen, V. Maliniemi, K. Mursula, (2016), 'Comparing the influence of sunspot activity and geomagnetic activity on winter surface climate', Journal of Atmospheric and Solar-Terrestrial Physics; doi:10.1016/j.jastp.2016.04.009.

Sato, M., Hansen, J. E., McCormick, M. P. and Pollack, J. B. (1993), Stratospheric aerosol optical depths (1850 1990), J. Geophys. Res., 98, 22, $987-22,994$.

Scaife, A, Ineson, S., Knight, J R, Gray, L., Kodera, K. and Smith, D. M. (2013), A mechanism for lagged North Atlantic climate response to solar variability, Geophysical Research Letters, 40, 2, 434-439.

Sobel A. H, Held I. M., and Bretherton C. S. (2002), The ENSO Signal in Tropical Tropospheric Temperature. J. Climate, 15, 2702-2706.

Sigmond, M., Scinocca J. F. and Kushner P.J. (2008), Impact of the stratosphere on tropospheric climate change. Geophysical Research Letters, 35, 12, DOI: 10.1029/2008GL033573.

Sigmond, M. and J. F. Scinocca, (2010), The influence of basic state on the Northern Hemisphere circulation response to climate change, J. Clim., 23, 1434-1446.

Stenchikov G, Delworth TL, Ramaswamy V, Stouffer, RJ, Wittenberg A and Zeng, F (2009), Volcanic signals in oceans, J. of Geophysical Research, 114, D16104, doi:10.1029/2008JD011673.

Toniazzo, T. and Scaife, A. A. (2006): The influence of ENSO on winter North Atlantic climate, Geophys. Res. Lett., 33, L24704, doi:10.1029/2006GL027881.

Thompson, D.W.J., Baldwin, M.P. and Wallace, J. M. (2002), Stratospheric Connection to Northern Hemisphere Wintertime Weather: Implications for Prediction, J. Clim, 15, 12, 1421-1428.

Trenberth, K.E. and Hoar T. J. (1996). The 1990-1995 El Niño-Southern Oscillation Event: Longest on record, Geophysical Research Letters, 23, 57-60.

Trenberth, K.E. and Hoar T. J. (1997). El Niño and climate change, Geophysical Research Letters, Vol. 24, 23, 3057-3060.

van Loon, H., G.A. Meehl, and D.J. Shea, (2007), Coupled air-sea response to solar forcing in the Pacific region during northern winter, J Geophys. Res.-Atmos., 112, D02108, doi: 10.1029/2006JD007378.

Vecchi, G.A., and Soden, B. J. (2007), Global Warming and the Weakening of the Tropical Circulation, J. Climate., 20, 4316-4340.

Visbeck, M.H., Hurrell JW, Polvani L and Cullen HM (2001), The North Atlantic Oscillation: Past, present, and future. Proceedings of the National Academy of Sciences, vol. 98 no. 23. 12876-12877, doi: 10.1073/pnas.231391598.

Wang, C and Fiedler, P.C. (2006), ENSO variability and the eastern tropical Pacific: A review. Progress in Oceanography 69, 239-266.

Wang, T, Ottera, O H, Gao, Y and Wang H (2012), The response of the north Pacific decadal variability to strong tropical volcanic eruptions, Clim Dyn. 39(12), 2917-2936.

White, W. B., J. Lean, D. R. Cayan, et al. (1997), Response of global upper ocean temperature to changing solar irradiance, J. Geophys. Res.-Oceans, 102(C2), 3255-3266.

Yeo S. R. and Kim K. Y. (2014), Global warming, low-frequency variability, and biennial oscillation: an attempt to understand the physical mechanisms driving major ENSO events. Climate Dynamics, 43: 771-786, DOI: 10.1007/s00382-013-1862-1.

Zhang, D., and M. J., McPhaden, (2006), Decadal variability of the shallow Pacific meridional overturning circulation: Relation to tropical sea surface temperatures in observations and climate change models, Ocean Modelling, 15, 3-4, 250-273.

Zhang, Q., Guan, Y. and Yang, H. (2008), ENSO Amplitude Change in Observation and Coupled Models. Advances in Atmospheric Sciences, 25, 3, 361-366.

(C) 2016 by the author; licensee Preprints, Basel, Switzerland. This article is an open access article distributed under the terms and conditions of the Creative Commons by Attribution (CC-BY) license (http://creativecommons.org/licenses/by/4.0/). 